\title{
Model of Excellence: From Individuals to Dynamic Capabilities
}

\author{
JAAKKO SIVUSUO \\ University of Vaasa, Finland \\ jaakko.sivusuo@gmail.com \\ HENRY SIVUSUO \\ University of Vaasa, Finland \\ henry.sivusuo@gmail.com \\ JOSU TAKALA \\ University of Vaasa, Finland \\ josu.takala@uwasa.fi
}

Nowadays dynamic capabilities, sustainable competitive advantage and competition are normal elements in today's business world. Organizations are constantly trying to survive in competition. This study is building a model which aims to clarify competitive advantage from the point of organization and its' individuals. This study is based on constructive method and as a result Model of excellence is build. This model consists two separate sections; value-driven and norm-driven. This model is going to clarify how organizations are able to gain competitive advantage in turbulent environments. Model is also one tool for dynamic capabilities and it can be used for assessing organizations' maturity. Model of excellence emphasizes the role of individuals for building and maintaining sustainable competitive advantage. Case study is also included. This study reveals how to use model of excellence in the field of project management. Case study shows how project management roles can be implement in Model of excellence.

Key words: dynamic capabilities, excellence, competitive advantage https://doi.org/10.26493/1854-4231.13.97-109

\section{Introduction}

Organizations in various industries have faced a lot of competition forcing many traditional organizations and also industries to face changes. Nowadays dynamic capabilities as a theory of strategic management has taken role in the field of sustainable competitive advantage. The role of the management and management systems are also facing difficulties through dynamic environments and competition. 
Theories of dynamic capabilities highlight the role entrepreneurial actions and innovations (Teece 2007). These can be seen as parts of appreciate-driven side of the model in this study. Many of the theories of dynamic capabilities are concentrated on the norm-driven side and the appreciate-driven side gets less attention. In the field of Dynamic capabilities can be found a few studies that discuss themes around norm- and value-driven sides (Teece 2012).

Also quality management theories that aim to excellence are concentrating on norm-driven side. They take part in organization processes, structures and management while culture and leadership are ignored (Sivusuo 2015). Nowadays organizations must be innovative, initiative and brave for doing things differently. This requires individuals with mentioned characteristics. Model of excellence is going to highlight this challenge also.

The aim of this study is to clarify both of these sides (norm-driven and value-driven) and their relation to organization excellence. As a result the model of excellence is built by using constructive study method. Constructive study method is going to compound a few models into one model. That model is called model of excellence.

Case study is also included. The case study is going to clarify the role of model of excellence in project management process and also in general the organisation's production point of view. This case study gives answer what model of excellence means in organisations.

\section{Literature Review}

\section{DYNAMIC CAPABILITIES AND COMPETITIVE ADVANTAGE}

Theory of dynamic capabilities is one fragment of strategic management. Competition and changes in business environment create challenges to organizations to maintain and build competitive advantage. For being successful organizations must have dynamic capabilities (Teece, Pisano, and Shuen 1997). Theory of dynamic capabilities is based on theory of resource based view (RBV) (Eisenhardt 1989). The RBW shows that if organizations have resources that are valuable, rare, inimitable and non-substitutable they can achieve sustainable competitive advantage (Barney 1991). Scholars have seen that RBW can't explain how organizations achieve and maintain competitive advantage in rapid markets where rapid technological changes and aggressive competition is common. Dynamic capabilities take base from resource based view and adds some components to explain the success in dynamic markets.

There are many definitions of dynamic capabilities but the most 
common definition is by Teece, Pisano, and Shuen (1997). Their definition is that dynamic capability means organizations ability to react to changes facing in the market. This includes ability to integrate, build and reconfigure internal and external capabilities. Individual level has a role in the dynamic capability framework. At the top management level entrepreneurial actions and leadership skills are necessary for building dynamic capabilities in organization (Teece 2012). Adner and Helfat (2003) define that dynamic capabilities are managerial actions for integrate, build and reconfigure capabilities. That is almost the same as Teece's but it lifts up the important role of management. It also brings focus to individual level capabilities and properties on individual level. Zahra, Sapienza, and Davidsson (2006) further point out the role of individuals as part of dynamic capabilities. They see that dynamic capabilities are management level abilities to re-organize organizations resource base and routines.

Dynamic capabilities also consist of elements that can be seen as processes. Teece (2007) divides dynamic capabilities in three separate sections also called three separate processes. These are sensing, seizing and reconfiguring. It is said that dynamic capabilities are not ad hoc actions, which are repeatable processes and routines. Eisenhardt and Martin (2000) also describe that elements of process are related to dynamic capabilities. Real life examples are strategic decision-making and $\mathrm{R} \& \mathrm{D}$ processes to name a few.

When talking about dynamic capabilities also the role of knowledge and learning has been brought up. Zollo and Winter (2002) see dynamic capabilities as learning routines and learning mechanisms. Accumulation of experience, knowledge transfer and knowledge codification can be seen as examples of learning mechanism. Learning mechanisms can be seen as a base for dynamic capabilities development and also operational routines development.

As a conclusion, dynamic capabilities can be seen as a twodimensional framework. From organizational point of view the role of processes are considered important. Also the role of individual and their abilities help build dynamic capabilities. There are many definitions of dynamic capabilities but the common factor is that they all are trying to explain organizational success in turbulent environments. Also, the ability to renew organization and it's resource base is mentioned almost in every definition of dynamic capability.

PYRAMID OF HUMAN CAPABILITIES

Hamel's (2007) pyramid of human capabilities is used as a base for model of excellence. Hamel divides individual's features and values 
FIGURE 1

Pyramid of Human Capabilities (adapted from Hamel 2007)
Zeal/

Passion

Creativity

Initiative

Intellect

Diligence

Obedience

in six separate sections. The picture of this pyramid is shown in figure 1. Next we have a short summary about the capabilities on the pyramid of human capabilities:

1. Obedience. Obedience means ability to receive instructions and comply with the rules. In practice these kinds of individuals come to work and do the same routine manoeuvres they must (show up and do the job).

2. Diligence. Diligent and hard-working individuals are trustworthy. They can take responsibility and stay organized. Diligent and hard-working individuals also work a lot while focusing on work. Working long hours is characterized in these individuals.

3. Intellect. Intelligent individuals are responsible of their work and bring out the best practices in organizations. In other words, they transform the tacit knowledge to explicit and by that they give it for the organization.

4. Initiative. Initiative individuals don't wait for instructions before they act. They are able take actions in their own. They take ownership for a problem, an opportunity before asking them. They are not bounded by a definition of their job.

5. Creativity. Creative individuals are requesting and also indomitable in their work. Innovative thinking can be found in creative individuals work. They scan the environment outside the organization, finding innovations and solutions. After that they try to implement what they have learned. They are able to question the current processes and way to work. They also constantly try to make things in a better way. Normal is not enough for them.

6. Zeal/Passion. On top of the pyramid is passion. Passion is needed 
FIGURE 2

Quadrangle of

Management (adapted

from Sivusuo 2015)

\begin{tabular}{|c|c|}
\hline Management & $\begin{array}{c}\text { Organisation } \\
\text { structures }\end{array}$ \\
\hline $\begin{array}{c}\text { Leadership } \\
\text { followership }\end{array}$ & $\begin{array}{c}\text { Organisation } \\
\text { culture }\end{array}$ \\
\hline
\end{tabular}

if intentions and goals want to be achieved. At this stage individuals feel their job is not only intellectually meaningful, it also has spiritual meaning to them.

Hamel shows that steps from 1 to 3 can be bought in the organization. Also, those steps are becoming global commodities nowadays. If organization develops only these three steps in its activities, they can only achieve mediocre. Organization won't achieve excellence developing only these first steps. In other words, organisations won't achieve sustainable competitive advantage by developing only stages from 1-3. This doesn't mean that organisations should not have these steps, it means that concentrating on only those won't guarantee competitive advantage.

Organization can reach sustainable competitive advantage by developing stages $4^{-6}$. These are basically something money can't buy. These are characteristics of individuals. Thus, organization's role is more to support individuals. These are also the most complex and hardest for managing. Management can not tell a person to be passionate about their work, passion comes from the individual itself (Hamel 2012). On the other hand, organization has the power to destroy steps $4^{-6}$ if it does not recognize and give opportunities for individuals. Initiative, creativity and passion need opportunities generated from within the organization. Opportunities include platforms where individuals can bring up their thoughts and also be able to act in an innovative way.

The quadrangle of management is shown in figure 2 . This quadrangle divides the elements of management through functional and practical differences. Figure 2 divides the elements in two parts; upper and lower part. Upper part includes management and organisation structures. These are something that can be drawn or written down. Good examples can be organisation chart, process mapping or written instructions for management models and practises.

The lower part of the quadrangle represents entities that are figurative. Lower part includes leadership, followership, culture and also values. These entities are related to people and their interactions. Management theories say that the lower part is more power- 
ful in helping organisation to achieve its desired results. However, both parts correlate strongly with each other, and successful management depends on the good control of these correlations. Also the lower part contributes much more for excellence than the upper part (Sivusuo 2015).

However, there are many organisations that are developing and controlling only the upper part of the quadrangle. And the reason behind that is because it is easy.

\section{Research Process: Constructive Method}

This study is based on constructive research method. The roots of the constructive research method can be found from accounting management from the 1980's (Lindholm 2008). The aim for constructive study method is to develop new information. This method usually starts from identification of the problem. The construct itself is trying to give an answer for an explicit problem (Kasanen and Lukka 1993).

Starting point or the problem of this study is that theories of dynamic capabilities highlight the process side of the firm (norm driven) while the value-driven side remains in a smaller role. More detailed definitions about these norm-driven and value-driven can be found from the results chapter.

Figure 3 highlights the links inside the constructive study method. The elements of constructive research can be divided in two parts; practice and theory. Predetermined practical problem and theory build around the problem are input data for construction. Weak market test, semi-strong market test and strong market test are the methods for validating the results from construction. At the same time the results can be reflected for current theories. In other words construction can be seen as a useful tool to generate new theories (Kasanen and Lukka 1993).

Lukka (2014) divides constructive approach in five elements (Oiva 2007):

1. Focus on a particularly relevant problem which has research potential and also the problem wants to be solved.

2. Generate new construction for problem solving.

3. Demonstrate that the solution works for example via weak market test.

4. Require cooperation with researchers and other representatives which also includes experimental learning. 


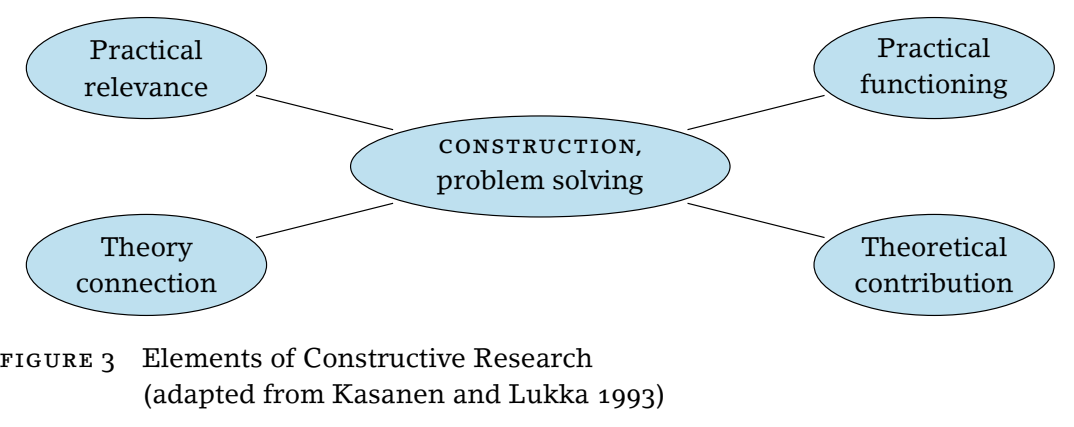

FIGURE 4

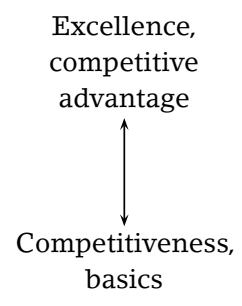

Model of Excellence

5. Show the theoretical connections and the research contribution of the solution concept.

\section{Results}

The excellence model build from construction can be found from figure 4 . The basic idea behind this model is to highlight issues behind competitiveness, competitive advantage and excellence. Model of excellence defines that excellence is always build on the conventional.

We divided model of excellence in two sections; norm-driven and value-driven. Norm-driven side includes elements for achieving mediocre results. Management and organisation structures can be put in this section from the management quadrangle. This is also the section, which can be influenced by organisation itself. Normdriven side also includes elements which money can by.

Value-driven side includes elements organisation can achieve resulting from excellency and it can be the best of its industry. This requires organizations to manage elements from the norm-driven side. Value-driven side brings up the role of individuals and also their personal capabilities. Organisations role is to lead opportunities.

One good example from value driven side is training. Training and engaging employees can be seen as a part of norm-driven side.

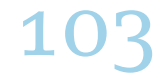


The role of value-driven side focuses on individuals. The question is if the individual takes part in training and if it's capable to apply learned skills in practice.

\section{NORM-DRIVEN SIDE}

Norm-driven side includes entities that can be written down or drawn in a picture. Examples of entities are instructions, process charts and written down organisation structure. Organisation has a large role in norm driven side. This means that organisation is able to decide what kind of instructions will be written and what of those to keep within the organisation unrecorded.

From the dynamic capability point of view, norm driven side is trying to put dynamics into static mode and also it is trying to bring things to more perceivable form. However, norm driven-side itself won't give sustainable competitive advantage to organisations. It can be said that norm-driven side is not going to generate nor maintain dynamic capabilities in an organisation.

Organisations that are guiding their actions via hard norm driven are not able to bring neither innovative thinking nor innovations inside the organisation. Organisation's management system is based on norm-driven if it's activities are instructed a lot. Every step and every action is based on some kind of instruction. Also reporting system, decision-making powers and response limits are written down in instructions. This also highlights the fact that norm-driven organisations will not encourage to arouse any radical innovations.

Thus the role of innovation is based more on continuous improvement. It allows progressive improvements inside organisation but not radical innovations. Some incremental innovations can be achieved through norm-driven side but major changes will not be implemented or permitted.

Norm-driven side includes actions that ensure the legality and safety of operations. Examples are laws, quality standards and different sector-specific regulations. Usually safety critical organisations have a lot of different kind of sector-specific regulations which are mandatory to follow.

In norm-driven side decision-making is based on facts, and only on facts. There is no need or room for feelings. Usually decisions are based on repayment calculations, return of investments or some other meter that is a fact. You can't make decision by saying 'I feel that this is the right direction/decision.'

Knowledge and its development has a huge role for building and maintaining sustainable competitive advantage. Knowledge devel- 
opment is based on training in norm-driven side. Through training activities organisations are aiming to tell how things get done.

Lower part of the pyramid involves on human capabilities; obedience, diligence and intellect included in norm-driven section. As mentioned earlier these attributes can be bought into organisation. Their duties can be fulfilled by given instructions. Learning is based on single-loop learning and audit is the main tool for checking is the organisation doing their business according to instructions. Audit findings and development themes are put on right track by singleloop learning. It can be said that by following norm-driven actions organisation is guided to operate on a basic quality standard level. Norm-driven actions are not sufficient to push organisation to an advanced level.

\section{VALUE-DRIVEN SIDE}

Dynamic capabilities demand entrepreneurial actions and innovations for achieving sustainable competitive advantage. These requirements can be found from value-driven side. While norm-driven side concentrates on organisation, processes and instructions, value driven side concentrates more on individuals. Management practices are based on transparency, freedom and experimental. Development by experimental is one key element in norm-driven side. Great value-driven management means genuinely learning from mistakes and also accepting failures. Organisation won't achieve value-driven stage if it strongly fears failures and making mistakes.

Passion, initiative and creativity require creating motivating possibilities from the management point of view. Organisation can allocate possibilities and individual's choice is to seize them. Organisation's responsibility is to recognize individuals who are passionate, initiative and creative. Subsequently organisations must generate the best platform to enable individual growth. These are the basics for value-driven model.

Decision-making accepts emotions as a part of decision. Resent research has seen that emotions and feelings have huge role in decision-making. Individual's emotions can overlap against traditional facts. Organisations role is to stabilize and mitigate emotion based decision-making during decisions. This happens via normdriven side.

Knowledge and its development also have huge role on valuedriven side. Basic training is needed but individuals must be put under thinking process. It is not enough that people know how to do things; they must also understand why things are done on that way. 
Organisation's role is to train and individual's role is to learn and understand. Divergent thinking has a role in training and individual understanding. Individuals must be able to change how they think and do things. Organisations and individuals must change how they think and how to make business in turbulent markets. These kind of operations require a highly developed organisation culture. Culture must be responsive for new ideas, thoughts and change. Advanced organisation culture needs to be maintained every day.

From the innovation point of view, value-driven model supports also radical innovations. Radical innovations are something that can shake current business, management and leadership models. Innovations from the value-driven model not only concentrate on improving current status, they also question current activities, processes and operational requirements.

The aim of learning is to raise the current level upwards inside value-driven model. In other words, by learning organisation is trying to achieve excellence. Instructions and standards are also necessary in value-driven side. Learning is based on double loop learning, which aims to arouse conversation about changes regarding current instructions and standards.

\section{Case Study: Project Management Process and the Model of Excellence}

This case study is based on project management point of view. It includes one case-organisation and its project management model. The case study is done by interviews with project process owner of the case-organisation. The owner is responsible for the whole project process and development related to it.

Project management model in case-organisation and also in general project management models recognizes a few key roles from field of project management. These roles are steering group, project owner, project manager and project team. The model of excellence is shown to the case organization's project process owner. The main question is that how the organization is able to implement the competences from the model of excellence to their current roles of the project management.

Persons in steering group must have strong ability to make decisions. These persons must solve escalated problems in the project. From the model of excellence point of view creativity and passion are characteristics for being successful in the field of project management. This includes also innovative thinking and ability to achieve the project's goal. 
Competences in leadership and management are mandatory for project owner in successful projects. Passion is the key from the point of model of excellence. Passion must be so high that project owner is willing to take projects success in part of his or her personal profit targets. As we can see these two roles can be put in the side of value driven model. Next two, project manager and project team, highlights the important role for norm-driven side.

Project manager must understand the overall project process, its tools, instructions and how to implement those. Project manager's task is to implement project towards the goal with provided resources. In successful projects project manager is part of the project team. This requires initiative and intellect abilities from model of excellence. Last but not least is the project team. Successful project team includes elements from the norm-driven side. Obedience and diligence are the desired features.

Case-organisation sees that the model of excellence can be implement in project management. This model is not black and white. We can emphasize different features for different roles in project management. Being successful in project management organisation must have all of the elements form the model of excellence. It also has to understand how to balance those elements while choosing right individuals into right positions. Case-organisation also sees that being successful in projects needs much more. Process descriptions and templates are not enough in competition. Organisation must understand the concept of Model of Excellence and implement it in their everyday operations.

\section{Conclusion and Discussion}

The model of excellence presented in this study brings new perspective compounding dynamic capabilities, excellence and roles of organisation and individuals. We can say that successful organisations are able to balance on both sides of the model of excellence. Those organisations are constantly executing activities on both sides aiming for excellence. Current status is never enough. Focusing on just one side of the model guarantees only mediocre results at its best. It can be said that organisations with dynamic capabilities are able to balance between value-and norm-driven models.

Model of excellence includes elements from theories of dynamic capabilities. Recourse based theory has influenced dynamic capabilities and it brings up the VRIN-attributes achieving sustainable competitive advantage. This theory says that competitive advantage can be achieved through resources, which are valuable, rare, inimitable 
TABLE 1 Norm- and Value-Driven Comparison

\begin{tabular}{lll}
\hline Theme & Norm-driven & Value-driven \\
\hline Competitive advantage & Short term & Long term \\
VRIN elements & Short term & Long term \\
Decision making & Traditional, based on facts & $\begin{array}{l}\text { Emotional, based on facts } \\
\text { and feelings }\end{array}$ \\
Knowledge management & Training & $\begin{array}{l}\text { Learning } \\
\text { Management/Leadership }\end{array}$ \\
& $\begin{array}{l}\text { Based on written models } \\
\text { and decision making pow- }\end{array}$ & Leadership based style \\
ers & Discouraging & Constructive \\
Innovation & Single-loop learning & Double loop learning \\
Learning & &
\end{tabular}

and non-substitutable. Model of excellence divides resources in two dimension; individuals and organisation. Model of excellence includes two sides; value-driven and norm-driven side and resources can be found also in both sides. Table 1 shows the main different between two sides of the model of excellence.

Basic idea of the model is to arouse conversation how organisations are seeing model of excellence in practice. Further research themes could concentrate on how organisations current resource allocations are constructed around model of excellence. Are organisations based more or completely on norm-driven side and how in practise are they operating in norm-driven side? Nowadays we can see that organisations are developing a lot their actions and processes via norm-driven side. Good examples from the field are LEANprojects and ensuring qualitative operations with standards.

Case study reveals that model of excellence can be connected in project management process. It also shows pragmatically how the ideas from the model of excellence can be implement in project management. Model of excellence gives good framework for developing assessment for organisations. This assessment can give results how mature dynamic capabilities organisation has. Model of excellence need much more market tests to evaluate its functionality. Through practical testing and case studies this model can be developed. Further research question could be how organisations see this model in their everyday operations. This model must be tested via case study, for example in an innovation process.

\section{References}

Adner, R., and C. E. Helfat. 2003. 'Corporate Effects and Dynamic Managerial Capabilities.' Strategic Management Journal 24 (10): 1011-25. 
Barney, J. 1991. 'Firm Resources and Sustained Competitive Advantage.' Journal of Management 17 (1): 99-120

Eisenhardt, K. M. 1989. 'Building Theories from Case Study Research.' Academy of Management Review 14 (4): 532-50.

Eisenhardt, K. M., and J. A. Martin. 200o. 'Dynamic Capabilities: What Are They?' Strategic Management Journal 21 (10-11): 1105-21.

Hamel, G. 2007. The Future of Management. Boston, MA: Harvard Business School Press.

- 2012. What Matters Now: How to Win in a World of Relentless Change, Ferocious Competition, and Unstoppable Innovation. San Francisco, cA: Jossey-Bass.

Kasanen, E., and K. Lukka. 1993. 'The Constructive Approach in Management Accounting Research.' Journal of Management Accounting Research 5:243-64.

Lindholm, A.-L. 2008. 'A Constructive Study on Creating Core Business Relevant скем Strategy and Performance Measures.' Facilities $26(7-8): 343-58$.

Lukka, K. 2014. 'Konstruktiivinen tutkimusote.' Metodix, 19 May. https:// metodix.fi/2014/o5/19/lukka-konstruktiivinen-tutkimusote/

Oiva, A. 2007. Strategiakeskeinen kyvykkyyden johtaminen ja organisaation strateginen valmius. Oulu: Oulun Yliopisto.

Sivusuo, H. 2015. 'How Values Guide an Organisation towards Excellence Case: The Finnish Air Force.' Paper presented at the 59th EOQ Quality Congress in Athens, 11-12 June.

Teece, D. J. 2007. 'Explicating Dynamic Capabilities: The Nature and Microfoundations of (Sustainable) Enterprise Performance.' Strategic Management Journal 28 (13): 1319-50.

- 2012. 'Dynamic Capabilities: Routines versus Entrepreneurial Action.' Journal of Management Studies 49 (8): 1395-401.

Teece, D. J., G. Pisano, and A. Shuen. 1997. 'Dynamic Capabilities and Strategic Management.' Strategic Management Journal 18 (7): 50933.

Zahra, S., H. Sapienza, and P. Davidsson. 2006. 'Entrepreneurship and Dynamic Capabilities: A Review, Model and Research Agenda.' Journal of Management Studies 43 (4): 917-55.

Zollo, M., and S. G. Winter. 2002. 'Deliberate Learning and the Evolution of Dynamic Capabilities.' Organization Science 13 (3): 339-51. 